Article

\title{
In Vitro Cytotoxicity and In Vivo Antitumor Efficacy of Tetrazolato-Bridged Dinuclear Platinum(II) Complexes with a Bulky Substituent at Tetrazole C5
}

\author{
Seiji Komeda ${ }^{1, *(\mathbb{D}}$, Masako Uemura ${ }^{1}$, Hiroki Yoneyama ${ }^{2}$, Shinya Harusawa ${ }^{2}$ and \\ Keiichi Hiramoto ${ }^{1}$ \\ 1 Faculty of Pharmaceutical Sciences, Suzuka University of Medical Science, Mie 513-8670, Japan; \\ masako-u@suzuka-u.ac.jp (M.U.); hiramoto@suzuka-u.ac.jp (K.H.) \\ 2 Department of Pharmaceutical Organic Chemistry, Osaka University of Pharmaceutical Sciences, \\ Osaka 569-1094, Japan; yoneyama@gly.oups.ac.jp (H.Y.); harusawa@gly.oups.ac.jp (S.H.) \\ * Correspondence: komedas@suzuka-u.ac.jp; Tel.: +81-59-340-0581
}

Received: 7 November 2018; Accepted: 24 December 2018; Published: 8 January 2019

\begin{abstract}
Tetrazolato-bridged dinuclear platinum(II) complexes ([\{cis-Pt $\left.\left(\mathrm{NH}_{3}\right)_{2}\right\}_{2}(\mu-\mathrm{OH})(\mu-5-\mathrm{R}-$ tetrazolato- $\mathrm{N} 2, \mathrm{~N} 3)]^{2+}$; tetrazolato-bridged complexes) are a promising source of next-generation platinum-based drugs. $\beta$-Cyclodextrin $(\beta-C D)$ forms inclusion complexes with bulky organic compounds or substituents, changing their polarity and molecular dimensions. Here, we determined by ${ }^{1} \mathrm{H}-\mathrm{NMR}$ spectroscopy, the stability constants for inclusion complexes formed between $\beta-\mathrm{CD}$ and tetrazolato-bridged complexes with a bulky, lipophilic substituent at tetrazole C5 (complexes 1-3, phenyl, n-nonyl, and adamantyl substitution, respectively). We then determined the in vitro cytotoxicity and in vivo antitumor efficacy of complexes 1-3 against the Colon-26 colorectal cancer cell line in the absence or presence of equimolar $\beta$-CD. Compared with the platinum-based anticancer drug oxaliplatin ( $1 R, 2 R$-diaminocyclohexane)oxalatoplatinum(II)), complex 2 had similar cytotoxicity, complex $\mathbf{3}$ was moderately cytotoxic, and complex 1 was the least cytotoxic. The cytotoxicity of the complexes decreased in the presence of $\beta-\mathrm{CD}$. When we examined the in vivo antitumor efficacy of complexes 1-3 (10 mg/kg) against homografted Colon-26 colorectal tumors in male BALB/c mice, they showed a relatively low tumor growth inhibition compared with oxaliplatin. However, in the presence of $\beta-C D$, complex 3 had higher in vivo antitumor efficacy than oxaliplatin, suggesting a new direction for future research into tetrazolato-bridged complexes with high in vivo antitumor activity.
\end{abstract}

Keywords: anticancer drug; cancer; cyclodextrin; drug discovery; platinum

\section{Introduction}

Platinum(II) coordination compounds are an important group of pharmacophores in cancer chemotherapy. The first $\mathrm{Pt}(\mathrm{II})$ coordination compound approved for clinical use was cisplatin (cis-diamminedichloridoplatinum(II)) in the 1970s [1-3], and since then, other related compounds have been developed-such as carboplatin (cis-diammine(1,1-cyclobutanedicarboxylato)platinum(II)) [4,5] and oxaliplatin (1R,2R-diaminocyclohexane)oxalatoplatinum(II)) [6,7]—which have fewer side effects than cisplatin and have been approved for different clinical applications (Figure 1). These Pt-based drugs remain some of the most utilized agents in current cancer chemotherapy. 
<smiles>N[Ge](Cl)(Cl)P(N)(N)(Cl)Cl</smiles>

(a)

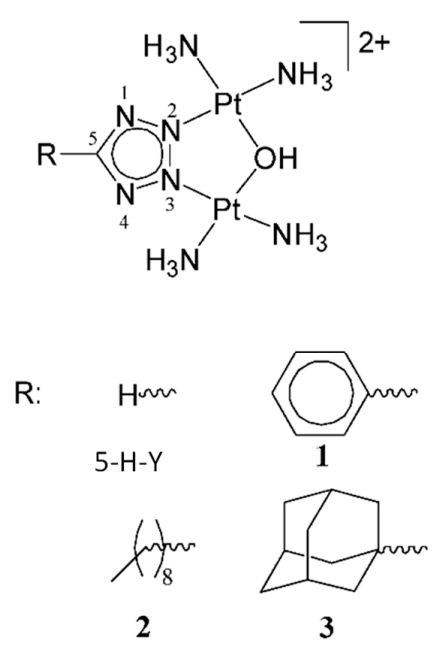

(b)

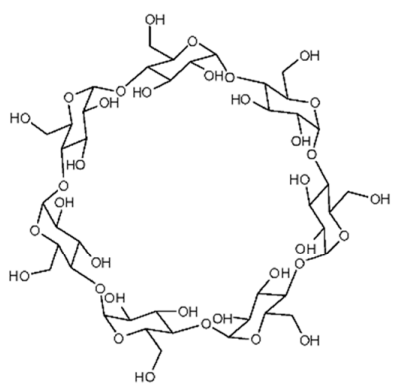

(c)

Figure 1. Chemical structures of (a) the platinum-based anticancer drugs cisplatin, carboplatin, and oxaliplatin, (b) the tetrazolato-bridged complexes 5-H-Y and 1-3, and (c) $\beta$-cyclodextrin ( $\beta$-CD).

Platinum(II) complexes with the general formula cis-[ $\left.\mathrm{PtL}_{2} \mathrm{X}_{2}\right]$ (where $\mathrm{L}=$ an ammine or amine, and $\mathrm{X}=\mathrm{a}$ leaving group, such as a halide or dicarboxylate) and antitumor efficacy are mostly much less effective against cisplatin-resistant cancer cells than against its parent cancer cells, due to their similar DNA-binding modes [8-10]. Therefore, we have been systematically modifying these general $\mathrm{Pt}$ (II) complexes [11-13] to provide structurally unconventional platinum complexes with antitumor spectra distinct from those of current platinum-based drugs [14-18].

The importance of the platinum-DNA interaction for antitumor efficacy has been shown for cisplatin, which forms covalent DNA adducts, such as 1,2-intrastrand and interstrand crosslinks [19-24], that induce local conformational changes in the DNA structure. Although these conformational changes are major determinants of the cytotoxicity of cisplatin, it remains unknown whether the most important factor in cytotoxicity is the formation of the DNA adducts themselves or the resulting conformational changes. We hypothesized that DNA adduct formation is the most important factor and thus designed azolato-bridged dinuclear $\mathrm{Pt}(\mathrm{II})$ complexes with the general formula $\left[\left\{\text { cis-Pt }\left(\mathrm{NH}_{3}\right)_{2}\right\}_{2}-(\mu-\mathrm{OH})(\mu \text {-azolato })\right]^{2+}$ (azolato = pyrazolato, 1,2,3-triazolato, or tetrazolato) [11-13] that can crosslink two adjacent nucleobases with minimal kinking of the double helix $[25,26]$ and escape from the DNA repair systems of tumor cells $[27,28]$. These complexes consist of two Pt(II) coordination spheres bridged by azolato and hydroxo anions, the latter of which acts as a leaving group, enabling bifunctional covalent binding to DNA. Due to their positive charges, these complexes have multimodal DNA binding modes [29,30], a characteristic that makes these series of complexes cytotoxic in many human tumor cell lines and circumvents the cross-resistance to cisplatin [31-34].

Recently, we reported the structure-activity relationships of a series of tetrazolato-bridged dinuclear platinum(II) complexes ([\{cis-Pt $\left.\left(\mathrm{NH}_{3}\right)_{2}\right\}_{2}-(\mu-\mathrm{OH})(\mu-5-\mathrm{R} \text {-tetrazolato-N2,N3) }]^{2+}$; tetrazolato-bridged complexes) with a diverse range of substituents introduced at tetrazole $\mathrm{C} 5$ of $\left[\left\{c i s-\mathrm{Pt}\left(\mathrm{NH}_{3}\right)_{2}\right\}_{2}-(\mu-\mathrm{OH})(\mu \text {-tetrazolato-N2,N3) }]^{2+}(5-\mathrm{H}-\mathrm{Y})\right.$ and concluded that this series was a promising source of next-generation platinum-based drugs. For instance, against the mouse homografted Colon-26 colorectal tumor, two of the derivatives exhibited much higher in vivo antitumor efficacy than oxaliplatin [35], which is currently used for the treatment of colorectal cancer.

To build on our previous research, here we report the in vitro cytotoxicity and in vivo antitumor efficacy of three tetrazolato-bridged complexes, each with a bulky, lipophilic substituent at tetrazole C5 $\left(\left[\left\{\text { cis- } \mathrm{Pt}\left(\mathrm{NH}_{3}\right)_{2}\right\}_{2}(\mu-\mathrm{OH})(\mu-5-\right.\right.$ phenyltetrazolato- $\mathrm{N} 2, \mathrm{~N} 3]\left(\mathrm{NO}_{3}\right)_{2} \quad$ (1), [\{cis-Pt $\left.\left(\mathrm{NH}_{3}\right)_{2}\right\}_{2}(\mu-\mathrm{OH})\left(\mu-5-\right.$ nonyltetrazolato-N2,N3] $\left(\mathrm{NO}_{3}\right)_{2}$ (2), and $\left[\left\{c i s-\mathrm{Pt}\left(\mathrm{NH}_{3}\right)_{2}\right\}_{2}(\mu-\mathrm{OH})(\mu-5-\right.$ 
adamantyltetrazolato- $\mathrm{N} 2, \mathrm{~N} 3]\left(\mathrm{NO}_{3}\right)_{2}$ (3)), against the Colon-26 colorectal cancer cell line. We hypothesized that the addition of the bulky, lipophilic substituents would increase the membrane permeability of the complexes and thereby increase antitumor efficacy. We also examined the effects of the presence of $\beta$-cyclodextrin ( $\beta-C D$ ) on the actions of the compounds because $\beta$-CD can form an inclusion complex with bulky organic compounds or substituents and change their polarity or molecular dimensions, thereby altering their efficacy compared with the non-complexed compound.

\section{Results}

\subsection{Determination of the Stability Constant of Inclusion Complexes with $\beta-C D$}

$\beta$-CD is a cyclic oligosaccharide comprising seven $(\alpha-1,4)$-linked D-glucopyranose units arranged in a doughnut shape, with a hydrophilic outer surface and a somewhat lipophilic central cavity (Figure 1). Generally, $\beta$-CD increases drug permeability through biological membranes and improves drug bioavailability. To find out if this is also true for tetrazolato-bridged complexes, we determined the stability constants $\left(K_{\mathrm{S}}\right)$ for inclusion complexes formed between complexes 1-3, oxaliplatin, or 5-H-Y and $\beta$-CD. The $K_{\mathrm{s}}$ values were determined from the ${ }^{1} \mathrm{H}-\mathrm{NMR}$ chemical shift of the $\mathrm{Pt}$ (II) complexes $(0.2 \mathrm{mM})$ in different concentrations of $\beta-\mathrm{CD}(0.2-2 \mathrm{mM})$ in $\mathrm{D}_{2} \mathrm{O}$ at $293 \mathrm{~K}$. The $K_{\mathrm{s}}$ values shown in Table 1 were obtained using the Benesi-Hildebrand equation [36-38], assuming a 1:1 guest/host interaction (Pt(II) complex/ $\beta-\mathrm{CD}$ ). For complexes 1-3, the observed linear correlation (Figure 2 ) confirmed that they formed a 1:1 inclusion complex with $\beta-C D$. No definite directional downfield/upfield shift or chemical shift change in protons originating from the guest compounds was observed for oxaliplatin or $5-\mathrm{H}-\mathrm{Y}$, in the presence of $\beta-\mathrm{CD}$, within the concentration range examined. This implied that they weakly associate with $\beta-C D$ and that the 1:1 inclusion complexes for complexes 1-3 were formed via interactions between the substituent at tetrazole $C 5$ and the lipophilic surface inside the $\beta-C D$ cavity. The highest stability constant was obtained for complex 3 (adamantyl group at tetrazole C5) and decreased by approximately one order of magnitude in the following order of complexes: $\mathbf{3}>\mathbf{2}$ (n-nonyl group at tetrazole C5) $>\mathbf{1}$ (phenyl group at tetrazole C5). The order of the stability constants was somewhat consistent with previously reported data: The stability constants for complexes containing adamantane moieties are between $10^{4}$ and $10^{5} \mathrm{M}^{-1}$ in water $[39,40]$, those for a series based on the cationic surfactant cetyltrimethylammonium bromide (CTAB) are mostly within the range of $10^{3}$ to $10^{4} \mathrm{M}^{-1}$ [41], and those for benzene [42] or phenylalanine [43] are less than $10^{3} \mathrm{M}^{-1}$. The $K_{\mathrm{s}}$ value for the inclusion complex between complex 3 and $\beta-C D$ indicates that they form a tight inclusion complex, in which the adamantyl group is located within the $\beta-C D$ cavity. It is generally considered that $\beta-C D$ affects drug biodistribution and elimination only when $K_{\mathrm{s}}$ is greater than $10^{5} \mathrm{M}^{-1}$ [44]. Therefore, the in vivo antitumor efficacy study described in later sections was performed with a 1:1 (molar ratio) mixture of complex 3 with $\beta-C D$, in addition to complex 3 alone, to examine how the formation of the $\beta$-CD inclusion complex affects tumor growth inhibition.

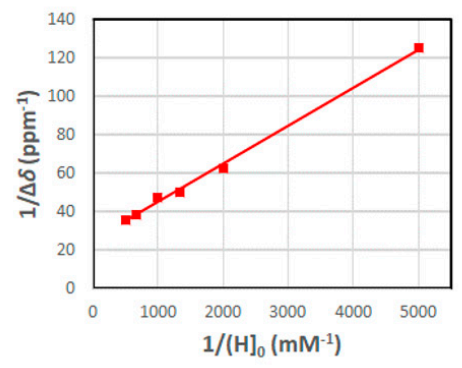

(a)

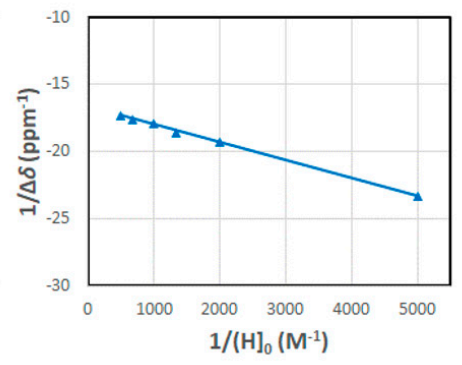

(b)

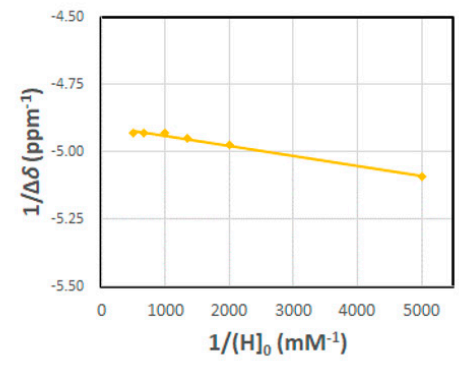

(c)

Figure 2. Benesi-Hildebrand plots of $0.2 \mathrm{mM}$ of complexes $1\left((\mathbf{a}) \mathrm{R}^{2}=0.997\right), 2\left((\mathbf{b}), \mathrm{R}^{2}=0.999\right)$ and $3\left((\mathbf{c}) \mathrm{R}^{2}=0.990\right)$ for various concentrations of $\beta-\mathrm{CD}(0.2-2 \mathrm{mM})$ at $293 \mathrm{~K}$ in $\mathrm{D}_{2} \mathrm{O}$, as assessed by ${ }^{1} \mathrm{H}$ NMR titration. 
Table 1. Stability constant $\left(K_{\mathrm{s}}\right)$ of $\mathrm{Pt}(\mathrm{II})$ complex/ $\beta$-cyclodextrin $(\beta-\mathrm{CD})$, as determined from the ${ }^{1} \mathrm{H}-\mathrm{NMR}$ chemical shift of $\mathrm{Pt}(\mathrm{II})$ complexes $(0.2 \mathrm{mM})$ in different concentrations of $\beta-\mathrm{CD}(0.2-2 \mathrm{mM})$ in $\mathrm{D}_{2} \mathrm{O}$ at $293 \mathrm{~K}$.

\begin{tabular}{cc}
\hline Pt(II) Complex & $K_{\mathbf{s}} / \mathbf{M}^{\mathbf{- 1}}$ \\
\hline Oxaliplatin & n. d. $^{\text {a }}$ \\
5-H-Y & n. d. $^{\text {a }}$ \\
$\mathbf{1}$ & $(1.81 \pm 1.28) \times 10^{3}$ \\
$\mathbf{2}$ & $(1.30 \pm 0.26) \times 10^{4}$ \\
$\mathbf{3}$ & $(1.27 \pm 0.03) \times 10^{5}$ \\
\hline
\end{tabular}

a Not determined since no definite directional downfield/upfield shift or no chemical shift change on protons originating from the guest compounds was observed.

\subsection{In Vitro Cytotoxicity}

We evaluated the in vitro cytotoxicity of four platinum(II) complexes-5-H-Y and complexes 1-3-against the Colon-26 colorectal cancer cell line in the absence or presence of equimolar $\beta-\mathrm{CD}$. Oxaliplatin was used as the positive control. The Colon-26 cells were exposed to each of the compounds for 24 or $48 \mathrm{~h}$, after which an MTS (3-(4,5-dimethylthiazol-2-yl)-5-(3-carboxymethoxyphenyl)-2-(4-sulfophenyl)-2H-tetrazolium, inner salt) assay was used to determine the half-maximal inhibitory concentrations $\left(\mathrm{IC}_{50}\right)$ of the complexes (Table 2). As expected, the longer exposure time $(48 \mathrm{~h})$ provided lower $\mathrm{IC}_{50}$ values for all of the tested compounds in the absence of $\beta-C D$. When the shorter exposure time was used $(24 \mathrm{~h})$, in the absence of $\beta-\mathrm{CD}, 5-\mathrm{H}-\mathrm{Y}$ had the highest cytotoxicity and was approximately 20 times more cytotoxic than oxaliplatin; complex 2 had a level of cytotoxicity similar to that of oxaliplatin, complex 3 was moderately cytotoxic, and complex $\mathbf{1}$ had the least cytotoxicity. $\beta-C D$ alone showed no cytotoxicity (data not shown). In the presence of $\beta-C D$, the cytotoxicity of each of the complexes decreased, particularly that of oxaliplatin (24-h exposure), complex 1 (48-h exposure) and 3 (both $24 \mathrm{~h}$ and $48 \mathrm{~h}$ exposure). Only complex 3 showed a marked decrease in cytotoxicity at both exposure times, probably because this complex possessed an adamantyl group and so likely formed a tight inclusion complex with $\beta-C D$, as indicated by the $K_{\mathrm{s}}$ value of the 1:1 inclusion complex. In contrast, for 5-H-Y, which did not have an additional substituent, and complex 2, which had a phenyl group at tetrazole $\mathrm{C} 5$, there was little difference between the $\mathrm{IC}_{50}$ values in the absence or presence of $\beta-\mathrm{CD}$ $(+\beta-\mathrm{CD} /-\beta-\mathrm{CD}$ ratio in Table 2$)$.

Table 2. In vitro cytotoxicity $\left(\mathrm{IC}_{50}\right)$ of oxaliplatin, $5-\mathrm{H}-\mathrm{Y}$, and derivatives of $5-\mathrm{H}-\mathrm{Y}$ with bulky substitutions at tetrazole $C 5$ (complexes 1-3) against Colon-26 colorectal cancer cells in the absence $(-\beta-C D)$ or presence $(+\beta-C D)$ of $\beta$-cyclodextrin $(\beta-C D)++\beta-C D /-\beta-C D$ values are the ratios of the mean $\mathrm{IC}_{50}$ values in the presence or absence of $\beta-\mathrm{CD}$.

\begin{tabular}{|c|c|c|c|}
\hline \multirow{2}{*}{ Pt(II) Complex } & \multicolumn{3}{|c|}{ Mean $\mathrm{IC}_{50} \pm \mathrm{SD} / \mu \mathrm{M}(n=6)$} \\
\hline & $-\beta-C D$ & $+\beta-C D$ & $+\beta-\mathrm{CD} /-\beta-\mathrm{CD}$ \\
\hline Oxaliplatin $(24 \mathrm{~h})^{\mathrm{a}}$ & $11 \pm 3$ & $28 \pm 3$ & 2.5 \\
\hline Oxaliplatin $(48 \mathrm{~h})^{\mathrm{b}}$ & $5.7 \pm 1.2$ & $7.9 \pm 0.3$ & 1.4 \\
\hline 5-H-Y $(24 h)^{a}$ & $0.59 \pm 0.21$ & $0.74 \pm 0.03$ & 1.3 \\
\hline $5-\mathrm{H}-\mathrm{Y}(48 \mathrm{~h})^{\mathrm{b}}$ & $0.23 \pm 0.09$ & $0.25 \pm 0.02$ & 1.1 \\
\hline $\mathbf{1}(24 \mathrm{~h})^{\mathrm{a}}$ & $>360$ & $>270$ & - \\
\hline $\mathbf{1}(48 \mathrm{~h})^{\mathrm{b}}$ & $43 \pm 1$ & $>270$ & $>6.3$ \\
\hline $2(24 h)^{a}$ & $6.3 \pm 0.7$ & $5.6 \pm 0.5$ & 0.9 \\
\hline $2(48 \mathrm{~h})^{b}$ & $4.9 \pm 0.6$ & $7.4 \pm 0.2$ & 1.5 \\
\hline $3(24 h)^{a}$ & $113 \pm 8$ & $>270$ & $>2.4$ \\
\hline $3(48 h)^{b}$ & $109 \pm 10$ & $>270$ & $>2.5$ \\
\hline
\end{tabular}

\footnotetext{
${ }^{a}$ Exposed to the $\mathrm{Pt}(\mathrm{II})$ complex for $24 \mathrm{~h} ;{ }^{\mathrm{b}}$ exposed to the $\mathrm{Pt}(\mathrm{II})$ complex for $48 \mathrm{~h}$.
} 


\subsection{In Vivo Antitumor Efficacy}

We examined the in vivo antitumor efficacy of complexes 1-3 against homografted Colon-26 colorectal tumors in male BALB/c mice. This was a preliminary study, in which the same dosage was used for all of the compounds tested, to ensure that the animals survived for at least one week. Complexes 1-3, oxaliplatin, or a 1:1 (molar ratio) mixture of complex 3 with $\beta$-CD were dissolved in $5 \%$ glucose and administered to the mice as a single dose $(10 \mathrm{mg}$ ( $\mathrm{Pt}$ complex $) / \mathrm{kg}$ ) via the tail vein on day 0 , which was 7 days after their inoculation with the Colon-26 colorectal cancer cells. No mice in any of the groups died and none showed significant body weight loss (Figure 3a). No marked tumor growth inhibition was observed in the mice treated with complexes 1-3: The mean terminal tumor volume in the mice treated with complexes 1-3 was $90 \%, 83 \%$, and $89 \%$ of that in the control group, respectively, and the value for oxaliplatin was $54 \%$ (Figure 3b). However, when complex 3 was administered as a 1:1 (molar ratio) mixture with $\beta-C D$, marked tumor growth inhibition was observed five times greater than that when complex 3 was administered alone (mean terminal tumor volume, $44 \%$ of that in the control group) and was slightly more effective than oxaliplatin (Figure $3 b$ ).

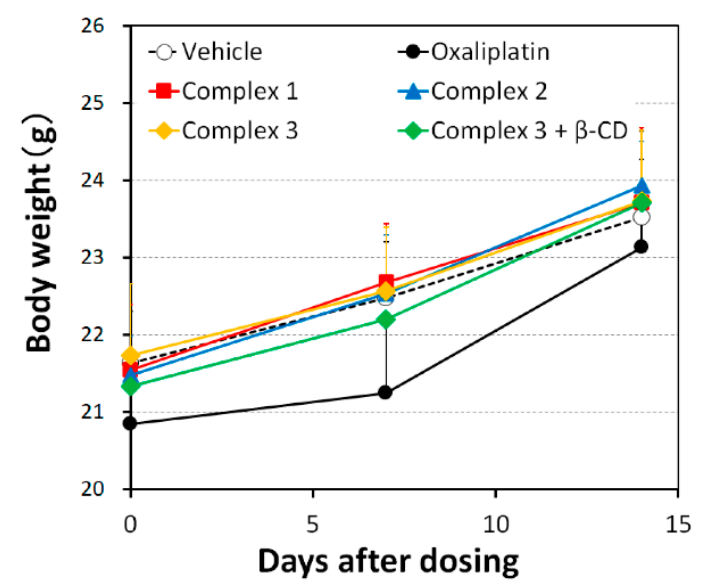

(a)

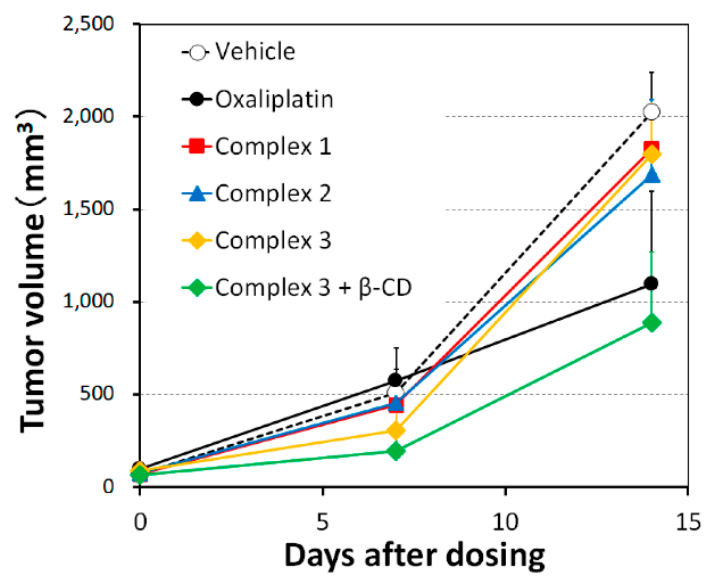

(b)

Figure 3. (a) Body weight and (b) tumor volume in male BALB/c mice laterally homografted with Colon-26 colorectal cancer cells and then treated with $10 \mathrm{mg} \mathrm{kg}^{-1}$ oxaliplatin, complexes 1-3, a 1:1 (molar ratio) mixture of complex 3 and $\beta$-cyclodextrin $(\beta-C D)$, or vehicle. Mice were treated with a single dose of the test compounds or vehicle on day 0 , which was 7 days after their inoculation with the Colon-26 colorectal cancer cells. Body weights and tumor volumes were measured weekly, starting on day 0 . Each data point represents the mean of six body weights or tumor volumes, and the error bars indicate standard deviations of the mean.

\section{Discussion}

Previously, we found that a variety of substitutions at tetrazole C5 increased the cytotoxicity of the tetrazolato-bridged complex, and that complexes with an ester group substituted at tetrazole $\mathrm{C} 5$, such as $\left[\left\{\text { cis-Pt }\left(\mathrm{NH}_{3}\right)_{2}\right\}_{2}(\mu-\mathrm{OH})(\mu\right.$-ethyl tetrazolato-5-carboxylate- $\left.\mathrm{N} 2, \mathrm{~N} 3)\right]\left(\mathrm{NO}_{3}\right)_{2}$ and $\left[\left\{c i s-\mathrm{Pt}\left(\mathrm{NH}_{3}\right)_{2}\right\}_{2}(\mu-\mathrm{OH})(\mu\right.$-propyl tetrazolato-5-acetate- $\left.\mathrm{N} 2, \mathrm{~N} 3)\right]\left(\mathrm{NO}_{3}\right)_{2}$, had much higher antitumor efficacies than oxaliplatin [35]. To build on this previous research, here we examined the efficacies of derivatives with bulky alkyl or aryl groups at tetrazole C5.

Compared with 5-H-Y, complexes 1-3 were much less cytotoxic against the Colon-26 cell line. Comparable results were obtained for cytotoxicity against L1210 murine leukemia cell lines [35]. Therefore, the introduction of bulky substituents tended to produce a lower in vitro cytotoxicity, possibly because the DNA interaction mode and cellular accumulation of complex $\mathbf{1}$ and $\mathbf{2}$ are distinct from those of 5-H-Y, and from other derivatives with a relatively small substituent at tetrazole $\mathrm{C} 5[34,45]$. The cytotoxicity of oxaliplatin and complex 3 was markedly decreased in the presence of equimolar $\beta-\mathrm{CD}$, whereas the cytotoxicity of 5-H-Y and complex 2 remained largely unchanged. Complex 3 
possesses an adamantyl group that forms a tight inclusion complex with $\beta-C D$, as indicated by the stability constant. $\beta-C D$ and other $C D$ s, and their inclusion complexes, are unable to cross the cell membrane. Therefore, the reduction in cytotoxicity induced by $\beta-C D$ could be due to a reduction in the speed of release of the platinum(II) complex from the $\beta$-CD inclusion complex.

Although the in vitro cytotoxicity results for complexes 1-3 suggest that the substitution of relatively bulky alkyl or aryl groups at tetrazole C5 is not a successful approach for improving antitumor efficacy, because $\beta$-CD decreased the cytotoxicity of the compounds, we did find in vivo that $\beta$-CD markedly enhanced the antitumor efficacy of complex 3 until it was higher than that of oxaliplatin. Some anticancer drugs complexed with a cyclodextrin have increased bioavailability and reduced toxicity, indicating that complexation with cyclodextrin changes the polarity and molecular dimensions of the compound. The present results suggest that the water solubility of complex 3 was increased by partial inclusion into $\beta-C D$, which covered the lipophilic part of the complex. Since opposite trends were observed in vitro and in vivo, the improved water solubility and increase in the molecular dimensions of complex 3 must have improved its delivery to the tumor site and reduced its cellular accumulation; the increase in the molecular dimensions likely means that the complex was unaffected by the enhanced permeability and retention effect. Together, the present results suggest that substitution with substituents bulkier than those examined here may be a promising means of identifying highly antitumor-active lead tetrazolato-bridged complexes.

With respect to methodology, the present in vivo study was a preliminary study in which the same dosage was used for all of the compounds tested to ensure that the animals survived for at least one week. Therefore, it is possible that the antitumor efficacy of the complexes can be increased by increasing the dosage. Furthermore, it may be possible to combine complex 3 with other $\beta-C D$ derivatives, such as methyl- $\beta-C D$, (2-hydroxyalkyl)- $\beta-C D$, or other specially functionalized cyclodextrins. Further studies are warranted. We have already designed and synthesized tetrazolato-bridged complexes with an adamantyl group linked by an ester or alkyl group at tetrazole $\mathrm{C} 5$, and in future experiments, we intend to find out which derivative is most suitable for complexation with $\beta$-CD.

\section{Materials and Methods}

\subsection{Materials}

Tetrazolato-bridged complexes with the formula [\{cis-Pt $\left.\left(\mathrm{NH}_{3}\right)_{2}\right\}_{2}(\mu-\mathrm{OH})(\mu-5-\mathrm{R}$-tetrazolato-N2,N3)] $\left(\mathrm{NO}_{3}\right)_{2}$ (complexes 1-3, 5-H-Y) were prepared using previously reported methods $[13,31,34,35]$. Oxaliplatin and $\beta-C D$ were purchased from Tokyo Chemical Industry (Tokyo, Japan) and Wako Pure Chemical (Osaka, Japan), respectively.

\subsection{Determination of Stability Constant}

The stability constant $\left(K_{\mathrm{s}}\right)$ of $\mathrm{Pt}(\mathrm{II})$ complex $/ \beta-\mathrm{CD}$ was determined by analysis of the ${ }^{1} \mathrm{H}-\mathrm{NMR}$ chemical shift of $\mathrm{Pt}$ (II) complexes $(0.2 \mathrm{mM})$ in different concentrations of $\beta-\mathrm{CD}(0.2-2 \mathrm{mM})$ in $\mathrm{D}_{2} \mathrm{O}$ at $293 \mathrm{~K}$. To prevent changes of the resonance frequency due to the formation of an inclusion complex between $\beta$-CD and the reference compound, 3-(Trimethylsilyl)propionic-2,2,3,3-d4 acid sodium salt (TSP), a solution of TSP in $\mathrm{D}_{2} \mathrm{O}$, sealed in a capillary tube, was placed inside an NMR tube. The NMR tube was then placed in the sample solution and used as the reference $(\delta=0)$. The $K_{\mathrm{s}}$ value was obtained by using the Benesi-Hildebrand Equation (1), assuming a 1:1 guest/host interaction (Pt(II) complex/ $\beta-\mathrm{CD})$ :

$$
1 / \Delta \delta=1 /\left(K_{\mathrm{s}} \Delta \delta_{\max }[\mathrm{H}]_{0}\right)+1 / \Delta \delta_{\max },
$$

where $\Delta \delta$ is the change in the ${ }^{1} \mathrm{H}-\mathrm{NMR}$ chemical shift, $\Delta \delta_{\max }$ is the maximum possible change in the ${ }^{1} \mathrm{H}-\mathrm{NMR}$ chemical shift, $[\mathrm{H}]_{0}$ is the total $\beta$-CD concentration, and $K_{\mathrm{s}}$ is the stability constant. 


\subsection{In Vitro Cytotoxicity Study}

The murine colorectal cancer cell line Colon-26 was provided by RIKEN BioResource Center through the National Bio-Resource Project of the Ministry of Education, Culture, Sports, Science, and Technology of Japan. The Colon-26 mouse colorectal cells were maintained in RPMI-1640 containing 10\% fetal bovine serum (Gibco; Life Technologies, Carlsbad, CA, USA), $100 \mathrm{U} / \mathrm{mL}$ penicillin, and $100 \mathrm{mg} / \mathrm{mL}$ streptomycin (Wako, Osaka, Japan) in a humidified atmosphere of $5 \% \mathrm{CO}_{2}$ at $310 \mathrm{~K}$. The Colon-26 cells $\left(3 \times 10^{4}\right.$ cells $/ \mathrm{mL} ; 100 \mu \mathrm{L} /$ well) were seeded onto 96-well microplates (Corning, Corning, NY, USA). All of the Pt(II) complexes tested, except for complex 2, were dissolved in water to prepare $4 \mathrm{mM}$ solutions. For assays in the presence of $\beta-\mathrm{CD}$, each $\mathrm{Pt}(\mathrm{II})$ complex solution was mixed with $12 \mathrm{mM} \beta-C D$ aqueous solution in a 1:1 molar ratio and incubated for at least $10 \mathrm{~min}$. Due to the low solubility of complex 2 , the concentrations of the solution or suspension of complex 2 were 0.25 or $1 \mathrm{mM}$ for assays in the absence or presence of $\beta-C D$, respectively. After sterilization by filtration, the solutions were diluted with water, and then $10 \mu \mathrm{L}$ of each diluted solution was added to the wells of the microplate. After incubation of the microplate for 23 or $47 \mathrm{~h}$ at $310 \mathrm{~K}, 10 \mu \mathrm{L}$ of Cell Counting Kit-8 solution (Nacalai Tesque, Kyoto, Japan) was added to each well, and the incubation was continued for an additional $1 \mathrm{~h}$ at $310 \mathrm{~K}$. The absorbance of each well at a wavelength of $460 \mathrm{~nm}$ was measured with a Spectra Max M5 microplate reader (Molecular Device; Orleans Drive Sunnyvale, CA, USA). Each experiment was performed independently for six wells per drug concentration. Half-maximal inhibitory concentrations $\left(\mathrm{IC}_{50}\right)$ were calculated as the concentration that provided $50 \%$ formazan production, relative to the control (no complex added), using the KaleidaGraph analytical software (version 4; Synergy Software, Reading, PA, USA).

\subsection{In Vivo Mouse Homografts}

The homograft study was performed using BALB/c mice (male, 4 weeks old; Japan SLC, Inc., Hamamatsu, Japan). The Colon-26 cells were maintained in $55-\mathrm{cm}^{2}$ dishes containing RPMI-1640 medium (Sigma-Aldrich (Merck), Darmstadt, HE, Germany) supplemented with 10\% fetal bovine serum (Gibco; Life Technologies, Carlsbad, CA, USA) containing $100 \mathrm{U} / \mathrm{mL}$ penicillin, and $100 \mathrm{mg} / \mathrm{mL}$ streptomycin. The cultures were grown in a humidified atmosphere of $5 \% \mathrm{CO}_{2}$ at $310 \mathrm{~K}$. Cells were grown to $80 \%-90 \%$ confluence and then harvested with $0.25 \%$ trypsin $/ 0.02 \%$ ethylenediaminetetraacetic acid (Sigma-Aldrich (Merck), Darmstadt, HE, Germany) before each subsequent passage.

The Colon-26 cells were subcutaneously injected into the lateral side of the mice ( 2 million cells/flank). About 7 days later (tumor diameter, ca. $8 \mathrm{~mm}$ ), the animals were randomly assigned to the following eight study groups ( $n=6$ per group): Control, oxaliplatin, $5-\mathrm{H}-\mathrm{Y}$, complexes $1-3$, and 1:1 (molar ratio) mixture of complex 3 and $\beta-C D$. Test substances were dissolved in $5 \%$ glucose and administered by single intravenous injection to the Colon-26 cell-bearing mice. The control group received $5 \%$ glucose (vehicle) only (total volume $=200 \mu \mathrm{L}$ ). The homograft tumor dimensions ( $d$ and $D$, shortest and longest dimensions of the tumor, respectively) were measured once a week with a digital caliper, and tumor volume $\left(\mathrm{mm}^{3}\right)$ was calculated by using the equation $d^{2} D / 2$. The body weights were measured weekly and statistically analyzed by means of one-way analysis of variance. This animal study was carried out with approval from the Institutional Animal Care and Use Committee of Suzuka University of Medical Science (Permission number: 34, 9 August 2017) and in accordance with all applicable institutional animal experimentation regulations.

\section{Conclusions}

The approval of cisplatin for clinical use prompted a search for novel platinum coordination compounds with improved efficacy. The tetrazolato-bridged complex can be greatly modified from the basic structure that is in current clinical use, and these modified complexes are an important group of potential next-generation platinum-based drug candidates. In the present study, the introduction 
of a bulky adamantyl group at tetrazole $\mathrm{C} 5$ provided the interesting finding that while the in vitro cytotoxicity of the modified complex was reduced in the presence of $\beta-C D$, its in vivo antitumor efficacy increased and was greater than that of the currently used colorectal cancer treatment, oxaliplatin. This finding indicates a new direction for further drug discovery research to provide tetrazolato-bridged complexes with high in vivo antitumor activity and less toxicity.

Author Contributions: Conceptualization, S.K.; methodology, S.K., M.U., H.Y., S.H. and K.H.; validation, S.K., M.U., H.Y., S.H. and K.H.; formal analysis, S.K., M.U. and K.H.; investigation, S.K., M.U. and K.H.; resources, S.K., H.Y. and S.H.; data curation, S.K.; writing-original draft preparation, S.K.; writing-review and editing, S.K., M.U., H.Y., S.H. and K.H.; visualization, S.K., M.U., H.Y., S.H. and K.H.; supervision, S.K. and S.H.; project administration, S.K.; funding acquisition, S.K.

Funding: This research was funded by a Japan Society for the Promotion of Science grant-in-aid (KAKENHI; grant number 15K07905).

Conflicts of Interest: The authors declare no conflict of interest.

\section{References}

1. Rosenberg, B.; VanCamp, L.; Trosko, J.E.; Mansour, V.H. Platinum compounds: A new class of potent antitumour agents. Nature 1969, 222, 385-386. [CrossRef] [PubMed]

2. Rosenberg, B.; VanCamp, L. The successful regression of large solid sarcoma 180 tumors by platinum compounds. Cancer Res. 1970, 30, 1799-1802.

3. Gottlieb, J.A.; Drewinko, B. Review of the current clinical status of platinum coordination complexes in cancer chemotherapy. Cancer Chemother. Rep. 1975, 59, 621-628. [PubMed]

4. Calvert, A.H.; Harland, S.J.; Newell, D.R.; Siddik, Z.H.; Jones, A.C.; McElwain, T.J.; Raju, S.; Wiltshaw, E.; Smith, I.E.; Baker, J.M.; et al. Early clinical studies with cis-diammine-1,1-cyclobutane dicarboxylate platinum II. Cancer Chemother. Pharmacol. 1982, 9, 140-147. [CrossRef] [PubMed]

5. Sharma, H.; Thatcher, N.; Baer, J.; Zaki, A.; Smith, A.; McAucliffe, C.A.; Crowther, D.; Owens, S.; Fox, B.W. Blood clearance of radioactively labelled cis-diammine 1,1-cyclobutane dicarboxylate platinum(II) (CBDCA) in cancer patients. Cancer Chemother. Pharmacol. 1983, 11, 5-7. [CrossRef]

6. Tashiro, T.; Kawada, Y.; Sakurai, Y.; Kidani, Y. Antitumor activity of a new platinum complex, oxalato (trans-1-1,2-diaminocyclohexane)platinum(II): New experimental data. Biomed. Pharmacother. 1989, 43, 251-260. [CrossRef]

7. Cvitkovic, E. Ongoing and unsaid on oxaliplatin: The hope. Br. J. Cancer 1998, 77 (Suppl. 4), 8-11. [CrossRef]

8. Seeber, S.; Osieka, R.; Schmidt, C.G.; Achterrath, W.; Crooke, S.T. In vivo resistance towards anthracyclines, etoposide, and cis-diamminedichloroplatinum(II). Cancer Res. 1982, 42, 4719-4725.

9. Eastman, A.; Illenye, S. Murine leukemia L1210 cell lines with different patterns of resistance to platinum coordination complexes. Cancer Treat. Rep. 1984, 68, 1189-1190.

10. Eastman, A.; Bresnick, E. Studies on the resistance of a murine leukemia L1210 cell line cis-diamminedichloroplatinum(II). Biochem. Pharmacol. 1981, 30, 2721-2723. [CrossRef]

11. Komeda, S.; Ohishi, H.; Yamane, H.; Harikawa, M.; Sakaguchi, K.-I.; Chikuma, M. An NMR study and crystal structure of [\{cis-Pt(NH3)2(9EtG-kN7)2(m-pz)][NO3]3 (9EtG = 9-ethylguanine) as a model compound for the 1,2-intrastrand GG crosslink. J. Chem. Soc. Dalton Trans. 1999, 17, 2959-2962. [CrossRef]

12. Komeda, S.; Lutz, M.; Spek, A.L.; Chikuma, M.; Reedijk, J. New antitumor-active azole-bridged dinuclear platinum(II) complexes: Synthesis, characterization, crystal structures, and cytotoxic studies. Inorg. Chem. 2000, 39, 4230-4236. [CrossRef] [PubMed]

13. Komeda, S.; Lin, Y.L.; Chikuma, M. A Tetrazolato-Bridged Dinuclear Platinum(II) Complex Exhibits Markedly High in vivo Antitumor Activity against Pancreatic Cancer. ChemMedChem 2011, 6, 987-990. [CrossRef] [PubMed]

14. Farrell, N.; Ha, T.T.; Souchard, J.P.; Wimmer, F.L.; Cros, S.; Johnson, N.P. Cytostatic trans-platinum(II) complexes. J. Med. Chem. 1989, 32, 2240-2241. [CrossRef] [PubMed]

15. Farrell, N.; Qu, Y. Chemistry of Bis(Platinum) Complexes-Formation of Trans Derivatives from Tetraamine Complexes. Inorg. Chem. 1989, 28, 3416-3420. [CrossRef] 
16. Farrell, N.; Kiley, D.M.; Schmidt, W.; Hacker, M.P. Chemical-Properties and Antitumor-Activity of Complexes of Platinum Containing Substituted Sulfoxides $\left[\mathrm{PtCl}\left(\mathrm{R}^{\prime} \mathrm{R}^{\prime \prime} \mathrm{SO}\right)(\right.$ Diamine $) \mathrm{NO}_{3}$. Chirality and Leaving-Group Ability of Sulfoxide Affecting Biological Activity. Inorg. Chem. 1990, 29, 397-403. [CrossRef]

17. Farrell, N.; Qu, Y.; Feng, L.; Van Houten, B. Comparison of chemical reactivity, cytotoxicity, interstrand cross-linking and DNA sequence specificity of bis(platinum) complexes containing monodentate or bidentate coordination spheres with their monomeric analogues. Biochemistry 1990, 29, 9522-9531. [CrossRef]

18. Farrell, N.; Qu, Y.; Hacker, M.P. Cytotoxicity and antitumor activity of bis(platinum) complexes. A novel class of platinum complexes active in cell lines resistant to both cisplatin and 1,2-diaminocyclohexane complexes. J. Med. Chem. 1990, 33, 2179-2184. [CrossRef]

19. Yang, D.; van Boom, S.S.G.E.; Reedijk, J.; van Boom, J.H.; Wang, A.H.J. Structure and isomerization of an intrastrand cisplatin-cross-linked octamer DNA duplex by NMR analysis. Biochemistry 1995, 34, 12912-12920. [CrossRef]

20. van Boom, S.S.; Yang, D.; Reedijk, J.; van der Marel, G.A.; Wang, A.H. Structural effect of intra-strand cisplatin-crosslink on palindromic DNA sequences. J. Biomol. Struct. Dyn. 1996, 13, 989-998. [CrossRef]

21. Shellard, S.A.; Fichtinger-Schepman, A.M.; Lazo, J.S.; Hill, B.T. Evidence of differential cisplatin-DNA adduct formation, removal and tolerance of DNA damage in three human lung carcinoma cell lines. Anticancer Drugs 1993, 4, 491-500. [CrossRef] [PubMed]

22. Takahara, P.M.; Rosenzweig, A.C.; Frederick, C.A.; Lippard, S.J. Crystal structure of double-stranded DNA containing the major adduct of the anticancer drug cisplatin. Nature 1995, 377, 649-652. [CrossRef] [PubMed]

23. Coste, F.; Malinge, J.M.; Serre, L.; Shepard, W.; Roth, M.; Leng, M.; Zelwer, C. Crystal structure of a doublestranded DNA containing a cisplatin interstrand cross-link at 1.63 A resolution: Hydration at the platinated site. Nucleic Acids Res. 1999, 27, 1837-1846. [CrossRef] [PubMed]

24. Jamieson, E.R.; Lippard, S.J. Structure, Recognition, and Processing of Cisplatin-DNA Adducts. Chem. Rev. 1999, 99, 2467-2498. [CrossRef] [PubMed]

25. Teletchea, S.; Komeda, S.; Teuben, J.M.; Elizondo-Riojas, M.A.; Reedijk, J.; Kozelka, J. A pyrazolato-bridged dinuclear platinum(II) complex induces only minor distortions upon DNA-binding. Chemistry 2006, 12, 3741-3753. [CrossRef]

26. Magistrato, A.; Ruggerone, P.; Spiegel, K.; Carloni, P.; Reedijk, J. Binding of novel azole-bridged dinuclear platinum(II) anticancer drugs to DNA: Insights from hybrid QM/MM molecular dynamics simulations. J. Phys. Chem. B 2006, 110, 3604-3613. [CrossRef]

27. Mlcouskova, J.; Kasparkova, J.; Suchankova, T.; Komeda, S.; Brabec, V. DNA conformation and repair of polymeric natural DNA damaged by antitumor azolato-bridged dinuclear Pt(II) complex. J. Inorg. Biochem. 2012, 114, 15-23. [CrossRef]

28. Mlcouskova, J.; Malina, J.; Novohradsky, V.; Kasparkova, J.; Komeda, S.; Brabec, V. Energetics, conformation, and recognition of DNA duplexes containing a major adduct of an anticancer azolato-bridged dinuclear Pt(II) complex. Biochim. Biophys. Acta 2012, 1820, 1502-1511. [CrossRef]

29. Imai, R.; Komeda, S.; Shimura, M.; Tamura, S.; Matsuyama, S.; Nishimura, K.; Rogge, R.; Matsunaga, A.; Hiratani, I.; Takata, H.; et al. Chromatin folding and DNA replication inhibition mediated by a highly antitumor-active tetrazolato-bridged dinuclear platinum(II) complex. Sci. Rep. 2016, 6, 24712. [CrossRef]

30. Uemura, M.; Yoshikawa, Y.; Yoshikawa, K.; Sato, T.; Mino, Y.; Chikuma, M.; Komeda, S. Secondand higher-order structural changes of DNA induced by antitumor-active tetrazolato-bridged dinuclear platinum(II) complexes with different types of 5-substituent. J. Inorg. Biochem. 2013, 127, 169-174. [CrossRef]

31. Komeda, S.; Takayama, H.; Suzuki, T.; Odani, A.; Yamori, T.; Chikuma, M. Synthesis of antitumor azolato-bridged dinuclear platinum(II) complexes with in vivo antitumor efficacy and unique in vitro cytotoxicity profiles. Metallomics 2013, 5, 461-468. [CrossRef] [PubMed]

32. Uemura, M.; Suzuki, T.; Nishio, K.; Chikuma, M.; Komeda, S. An in vivo highly antitumor-active tetrazolato-bridged dinuclear platinum(II) complex largely circumvents in vitro cisplatin resistance: Two linkage isomers yield the same product upon reaction with 9-ethylguanine but exhibit different cytotoxic profiles. Metallomics 2012, 4, 686-692. [CrossRef] [PubMed]

33. Uemura, M.; Hoshiyama, M.; Furukawa, A.; Sato, T.; Higuchi, Y.; Komeda, S. Highly efficient uptake into cisplatin-resistant cells and the isomerization upon coordinative DNA binding of anticancer tetrazolato-bridged dinuclear platinum(II) complexes. Metallomics 2015, 7, 1488-1496. [CrossRef] 
34. Komeda, S.; Yoneyama, H.; Uemura, M.; Muramatsu, A.; Okamoto, N.; Konishi, H.; Takahashi, H.; Takagi, A.; Fukuda, W.; Imanaka, T.; et al. Specific Conformational Change in Giant DNA Caused by Anticancer Tetrazolato-Bridged Dinuclear Platinum(II) Complexes: Middle-Length Alkyl Substituents Exhibit Minimum Effect. Inorg. Chem. 2017, 56, 802-811. [CrossRef] [PubMed]

35. Komeda, S.; Yoneyama, H.; Uemura, M.; Tsuchiya, T.; Hoshiyama, M.; Sakazaki, T.; Hiramoto, K.; Harusawa, S. Synthesis and Structure-Activity Relationships of Tetrazolato-Bridged Dinuclear Platinum(II) Complexes: A Small Modification at Tetrazole C5 Markedly Influences the In Vivo Antitumor Efficacy. J. Inorg. Biochem. 2019. [CrossRef] [PubMed]

36. Hanna, M.W.; Ashbaugh, A.L. Nuclear Magnetic Resonance Study of Molecular Complexes of 7,7,8,8-Tetracyanoquinodimethane and Aromatic Donors1, 2. J. Phys. Chem. 1964, 68, 811-816. [CrossRef]

37. Benesi, H.A.; Hildebrand, J. A spectrophotometric investigation of the interaction of iodine with aromatic hydrocarbons. J. Am. Chem. Soc. 1949, 71, 2703-2707. [CrossRef]

38. Mathur, R.; Becker, E.D.; Bradley, R.B.; Li, N.C. Proton magnetic resonance studies of hydrogen bonding of benzenethiol with several hydrogen acceptors. J. Phys. Chem. 1963, 67, 2190-2194. [CrossRef]

39. Eftink, M.R.; Andy, M.L.; Bystrom, K.; Perlmutter, H.D.; Kristol, D.S. Cyclodextrin inclusion complexes: Studies of the variation in the size of alicyclic guests. J. Am. Chem. Soc. 1989, 111, 6765-6772. [CrossRef]

40. Leong, N.J.; Prankerd, R.J.; Shackleford, D.M.; Mcintosh, M.P. The Effect of Intravenous Sulfobutylether7$\beta$-Cyclodextrin on the Pharmacokinetics of a Series of Adamantane-Containing Compounds. J. Pharm. Sci. 2015, 104, 1492-1498. [CrossRef]

41. Carlstedt, J.; Bilalov, A.; Krivtsova, E.; Olsson, U.; Lindman, B.R. Cyclodextrin-surfactant coassembly depends on the cyclodextrin ability to crystallize. Langmuir 2012, 28, 2387-2394. [CrossRef] [PubMed]

42. Trofymchuk, I.; Belyakova, L.; Grebenyuk, A. Study of complex formation between $\beta$-cyclodextrin and benzene. J. Incl. Phenom. Macrocycl. Chem. 2011, 69, 371-375. [CrossRef]

43. Kahle, C.; Holzgrabe, U. Determination of binding constants of cyclodextrin inclusion complexes with amino acids and dipeptides by potentiometric titration. Chirality 2004, 16, 509-515. [CrossRef] [PubMed]

44. Jansook, P.; Ogawa, N.; Loftsson, T. Cyclodextrins: Structure, physicochemical properties and pharmaceutical applications. Int. J. Pharm. 2018, 535, 272-284. [CrossRef] [PubMed]

45. Uemura, M.; Yoshikawa, Y.; Chikuma, M.; Komeda, S. A circular dichroism study uncovers a two-step interaction of antitumor azolato-bridged dinuclear platinum(II) complexes with calf thymus DNA. Metallomics 2012, 4, 641-644. [CrossRef] 